\title{
A SURVEY OF HARMONIC CURRENTS AT SEVERAL INDUSTRIES IN SRI LANKA
}

\author{
C. J. GAJANAYAKE ${ }^{1}$, G. RAMTHARAN ${ }^{2}$, G. K SAMARAWEERA ${ }^{3}$, A. ATPUTHARAJAH4*, J. B. \\ EKANAYAKE ${ }^{4}$
}

1 School of Electrical and Electronic Engineering,Nanyang Technological University Singapore.

2 School of Electrical and Electronic Engineering, University Of Manchester, Manchester, United Kingdom.

${ }^{3}$ Hayles Industrial Solutions Limited, 25, Foster Lane, Colombo 10.

${ }_{4}$ Department of Electrical and Electronic Engineering, University of Peradeniya, Peradeniya.

(Accepted: 28 June 2005)

\begin{abstract}
Since early 1980s there has been rapid growth in the demand for electricity from the industrial and domestic consumers in Sri Lanka. This resulted from various types of electrical, electronic and computer equipment, which pollute the electrical system being brought into the country. One of the major impacts that emerged due to these loads is the introduction of harmonics into the power system. In this paper, consequences of high level of harmonics in the power system is discussed. Measurements on individual loads of a number of industries were used to demonstrate that the harmonic levels present in our power system are approaching the limits specified in international standards such as IEEE 519 and G5/3. In order to minimize the consequence of this upward trend in harmonic pollution, long term and shortterm suggestions are also discussed.
\end{abstract}

Key words: harmonics, IEEE standards, Sri Lankan industries, power quality.

\section{INTRODUCTION}

Recent developments in power electronics and packaging technologies has led to efficient and automated controllable power converters in industry such as variable speed drives, ac-dc converters and inverters., ${ }^{1,2,3}$ Even though these devices are highly efficient, they distort the current waveform due to the non-linear characteristics. ${ }^{4}$

In Sri Lanka, a number of highly automated large industries were started in the last few decades. This resulted in increased penetration of non-linear loads, thus increasing harmonics injection into the power system. The high harmonic level introduces serious problems such as resonance, low power quality and malfunction of sensitive loads. Therefore, there is a responsibility on the utilities and consumers to reduce the harmonic level and maintain reliability and quality of the power supply. This can only be done by introducing proper harmonic standards such as IEEE STD $519^{5}$, British Harmonic Standards $(G 5 / 3)^{6}$ and forcing the consumers to comply with the standard. ${ }^{7}$

The main objective of the survey was to take measurements of harmonic levels present in a number of factories and to verify whether the harmonic levels comply with the available standards. It is intended to give suggestions regarding the limits of harmonic pollution level in Sri Lanka. The areas where extra attention should be taken to limit the harmonic levels to an acceptable limit are also highlighted. The survey was carried out at several industries in Sri Lanka covering Tea factories, Garment factories and Rubber manufacturing Industries.

\section{Effects of harmonics}

Effect on power system: Harmonic penetration into the power system network depends mainly on the characteristic of the network impedance. Usually the utility source impedance is much lower than the parallel path offered by other loads, and therefore the harmonic current tends to flow towards the utility and spread into the network. The higher harmonic current flows when the power system network is at resonance conditions. At the resonance frequency, combination of network capacitance and inductance reduce the impedance and amplify the level of harmonic current flowing in the power system network..$^{8,9}$

Disadvantages of the network resonance are: (i) the resulting high voltage distortion at

${ }^{*}$ Corresponding author 
some specific points in the power system network, (ii) higher order harmonic currents increaseing the heating and dielectric stress on capacitors, and (iii) an increase in copper losses, stray losses, eddy current and hysterisis losses in the transformers in the power system network.

Effect on sensitive equipments: Operation of the precise electronic equipment such as digital clocks and variable speed drives depend upon accurate determination of the voltage zero crossing and shape of the voltage waveform. Therefore, any distortion in the voltage waveform may lead to malfunction of these equipment. Equipment such as computers, Digital Signal Processing (DSP) hardware and programmable controllers can be affected by the harmonic current flowing through them or the magnetic coupling with the components of these equipment.

Effect on rotating machinery: A major effect of harmonic voltages and currents on rotating machinery is increased heating due to core and conduction losses at the harmonic frequencies. Also harmonic pairs create pulsating torque: for example, the fifth and seventh order harmonic current produce torque components that pulsate at the sixth harmonic frequency. ${ }^{10}$ This mechanical oscillation cause shaft fatigue and may affect the sensitive loads in the same installation.

\section{Standards}

Available standards: The effect of harmonics are well known and to limit it various countries have imposed limits by means of standards. Several standards have been published around the world to specify the effects and limitations on harmonic injection. Among them IEEE 519, G5/4, G5/3, and EN 61000-3-2 impose limits and give recommendation for both utility and consumer. In this project, IEEE 519 and G5/3 were used as references.

Harmonic limitations of IEEE 519 standard and the Engineering recommendation $6.5 / 3$

(a) IEEE 519 standard ${ }^{5}$ : This recommended practice gives guidance for the design of electrical power system, which includes both linear and nonlinear loads. In summary, this standard analyses the harmonic producing loads, system characteristics, effect of harmonics, and then gives the methods of measurement, and finally recommends practices for both consumers and utility. Table 1 specifies the acceptable current harmonic injection level as specified in IEEE 519 regulation. The limitation on the voltage harmonic distortion is indicated as $3.0 \%$.

Table 1, shows that as the rating of the user load decreases with respect to the short circuit level of the system, the percentage of harmonic current that the user is allowed to inject into the utility system increases, thus allowing higher harmonic injection into a stronger system. Therefore short circuit level at the point of connection should be determined to calculate the exact limitation on the Total Demand Distortion in current $\left(\mathrm{TDD}_{\mathrm{I}}\right)$ and Total Harmonic Distortion in current $\left(\mathrm{THD}_{\mathrm{I}}\right)$ up to $11^{\text {th }}$ order.

Table 1: IEEE 519 Total Demand Distortion for General Distribution Systems (120V through 69kV)

\begin{tabular}{ccc}
\hline $\begin{array}{c}\text { Short circuit to } \\
\text { fundamental ratio } \\
\left(\mathrm{I}_{\mathrm{sc}} \mathrm{I}_{\mathrm{I}}\right)\end{array}$ & $\begin{array}{c}\text { Total Hamonic } \\
\text { Distortion } \\
\left(\mathrm{THD}_{\mathrm{I}}^{\mathrm{k}}\right)\end{array}$ & $\begin{array}{c}\text { Total Demand Distortion } \\
\left(\mathrm{TDD}_{\mathrm{I}}{ }^{* *)}\right)\end{array}$ \\
\hline$<20$ & 4 & 5 \\
$20-50$ & 7 & 8 \\
$50-100$ & 10 & 12 \\
$100-1000$ & 12 & 15 \\
$>1000$ & 15 & 20 \\
\hline
\end{tabular}

Notes: \# THD stands for the total harmonic distortion, which is defined at the point of common coupling. \#\# TDD stands for total demand distortion, which is the harmonic current distraction in \% of maximum demand load current (15 or 30 min demand) 
(b) G.5/3 Recommendations ${ }^{6}$ : This recommendation specifies acceptance criteria for non-linear loads and also specifies the limits of harmonic currents and voltages that should be maintained by the consumers. It also states that the Short Circuit Level (SCL) should not be unduly low.

Table 2 shows the G.5/3 allowable individual harmonic current limitations for consumers at the Point of Common Coupling (PCC). This table can be used only if the $\mathrm{THD}_{\mathrm{v}}$ at the PCC is less than (i) $3.75 \%$ for $415 \mathrm{~V}$ and (ii) $3 \%$ for 6.6 to $11 \mathrm{kV}$. As the limitation is implemented with $\mathrm{THD}_{\mathrm{V}}$ and $\mathrm{THD}_{\mathrm{I}}$, it is not necessary to know the exact value of SCL. For a new customer, in order to obtain the connection, he should prove the harmonic levels of his system are within the limits. For an exiting customer, to connect a new non-linear load, they should calculate the harmonic levels after introducing the new load.

\section{Measurement and analysis of data}

Overview of companies: The industrial sector which uses large loads could be considered as the major source of harmonics. According to the CEB Statistical Digest, 2003, about $34 \%$ of the electricity is used in industries. Industrial sectors could also be sub divided into a number of subsectors, however selecting a sample space for harmonic measurements was very difficult. Further, access to factories in order to take measurements was also generally restricted. Therefore measurements were taken from five factories, which were broadly falling into clothing, tea processing and rubber sectors. According to the Annual Report of the Central Bank, 2003 these sectors are major exports in Sri Lanka accounting approximately $50.1 \%, 13.3 \%$ and $4.5 \%$ of the foreign income respectively. In the absence of exact statistics of number and size of factories in each sector, the above figures give an indirect indication about their dominancy in our industrial sector.

The type of products and the load ratios in each factory are given in Table 3.

Company " $A$ " is a rubber processing company and it produces rubber sheets required by the other joint companies. It is basically compounding raw rubber to the required standards. The main loads are induction motor based mixers and rolling machines.

Company "B" is a tea factory, which produces tea for export market. This company also dominated with induction motors used for grinding the tea leaves and for fermentation processes. In this factory $80 \%$ of the load is Variable Speed Drive (VSD) driven motors.

Company "C" produces quality garments for export market. A very large washer and the dryers are the main harmonic sources. Some of the dryer loads were driven by variable frequency drives while others were constant speed three phase induction motor loads.

Company " $D$ " is engaged in producing quality threads for the Garment Industry. Main machinery of the company includes the winding machines, steam power plant, water treatment unit and the dyeing section. The dyeing section is the major load, where induction motors are used to pressurize the dye paste. It is identified that the variable speed drives in the winding section and the RF dryers are the major harmonic generators.

Table 2: G.5/3 harmonic current limitations for any consumer at Point of Common Coupling (PCC)

\begin{tabular}{cccccccc}
\hline Supply $(\mathrm{kV})$ & \multicolumn{8}{c}{ Harmonic current (A r.m.s) } \\
\cline { 2 - 8 } & $2^{\text {nd }}$ & $3^{\text {rd }}$ & $5^{\text {th }}$ & $7^{\text {th }}$ & $9^{\text {th }}$ & $11^{\text {th }}$ & $12^{\text {th }}$ \\
\hline \multirow{2}{*}{0.415} & 48 & 34 & 56 & 40 & 8 & 19 & 16 \\
$6.6 \& 11$ & 13 & 8 & 10 & 8 & 3 & 7 & 6 \\
\hline
\end{tabular}


Company " $\mathrm{E}$ " is a complete tea factory, which is used to carry out tea manufacturing for experiment purpose. It also processes the tea leaves taken from their Estate. This factory mainly consists of induction motor loads, lighting loads and VSD controlled induction motors, where VSD is the main contributor towards harmonic production.

\section{Analysis on individual loads}

The industry uses several types of loads to convert electrical energy to other forms of energy. The most common types of harmonic producing loads are the Induction Motors (I/M) with VSD, dc motor (DC) drives, a large number of computers and fluorescent lamps. ${ }^{11,12}$

Measurements were carried out in the laboratory or on site to investigate the harmonic contribution from each load. A digital power meter together with a data logger was used to record active, reactive and apparent power; current; voltage; power factor; $\mathrm{THD}_{\mathrm{v}}$, $\mathrm{THD}_{\mathrm{I}}$, and odd harmonics up to $13^{\text {th }}$ harmonics continuously.

Table 4 shows the harmonic content of some of the commonly used loads, based on the measurements taken from the laboratory and on site. Table 5 shows the measured average values of $5^{\text {th }}, 7^{\text {th }}, 11^{\text {th }}, 13^{\text {th }}$ order harmonics, $\mathrm{THD}_{\mathrm{I}}$ and $\mathrm{THD}_{\mathrm{v}}$ for some of the loads in factories which are dominant harmonic sources. following:

Harmonic measurement reveals the

\begin{tabular}{llccccc}
\hline \multirow{2}{*}{ Company } & \multirow{2}{*}{ Type of product } & \multicolumn{4}{c}{ Electrical data } \\
\cline { 3 - 6 } & & Transformer & \multicolumn{4}{c}{ Load ratio (\%) } \\
\cline { 3 - 6 } & rating (kVA) & I/M & VSD & DC & Other loads \\
\hline \multirow{2}{*}{ A } & Rubber & 1000 & 75 & 5 & 5 & 15 \\
B & Tea & 200 & 65 & 15 & 10 & 10 \\
C & Garment & $630 \times 2$ & 70 & $7^{*}$ & 7 & 16 \\
D & Garment & 500 & 60 & 20 & 8 & 12 \\
E & Tea & 200 & 70 & 15 & 5 & 10 \\
\hline
\end{tabular}

Note: \# refers the VSDs are used to change the direction of rotation a) The second order harmonic current is very low for all the loads.

b) The third order harmonic current, was low for three-phase loads but high for single-phase loads.

c) Most of the current harmonic distortion was caused by the fifth harmonics.

Variable Speed Induction Motor Drive (VSD): Induction motors consume nearly half of the generated electricity in developed countries. ${ }^{13}$ Power electronics, Pulse Width Modulation (PWM) inverter (Current-fed or Voltage-fed) drives provide improved electromechanical performance, significant energy savings and controllability compared to constant speed motors. ${ }^{13}$

Table 4 and 5 shows $\mathrm{THD}_{\mathrm{I}}$ for a number of VSDs. According to these tables THD is about $70 \%$ for most of the cases except VSDs in winding machines in company $\mathrm{D}$. In the case of winding machines, measured VSD is the cumulative $\mathrm{THD}_{\mathrm{I}}$ for a large number of low rated motors. It is proposed in ${ }^{14}$ that when a large number of harmonic sources are connected in parallel, there will be a harmonic cancellation effect. However, before coming to conclusion further studies are required.

$D C$ motor servo system: Since dc-motor drives are simpler, cheaper and accurate, the dc-motors are used in industries for precise position and speed control applications. A rectifier is used in the supply, which injects large amount of harmonic

\section{Table 3: Company details}


currents during transient periods of the dc-motor operation. This is because the servo system requires large currents during sudden changes. ${ }^{15}$

Figure 1 shows the $\mathrm{THD}_{\mathrm{I}}$ and $\mathrm{THD}_{\mathrm{V}}$ variation of an industrial dc-motor drive used for rubber conditioning process. This machine was operated at about $200 \mathrm{kVA}$. It was measured that full load to no load fundamental current ratio is two. However, $\mathrm{THD}_{\mathrm{I}}$ is more than $12 \%$ during the full load period, i.e. for about 200 to 250 seconds.

In this particular company, the dc-motor system was supplied using a separate transformer. The graph shows that the $\mathrm{THD}_{\mathrm{v}}$ varies in a similar pattern as the $T H D_{1}$ during the same load cycle. This is due to the transformer impedance, which reduces the strength of the system at secondary terminals. From Tables 4 and 5 , the dc-motor system injects high amount of fifth order harmonic and significant amount of seventh, and eleventh order harmonics into the power system.

Electronic equipment: Modern electronic equipments such as Personal Computers (PCs), and Energy saving lamps inject harmonic current into the power system, because they are powered by rectified supplies. Low power electronic equipment such as PCs, Compact Fluoresent Lamps (CFL) lamps and fluorescent lamps with electronic ballasts are usually neglected when considering the harmonic contribution. However in industries, these types of loads are used in large numbers and estimating their harmonic contribution is essential. For this reason harmonic contribution of these loads were measured in the laboratory and given in Table 4.

Power Factor Correction (PFC) Capacitor: Possibility of system resonance is a major concerning factor when capacitors are connected to the power system. Combination of capacitor banks and line or/and transformer inductances causes series resonance; this offers a lowimpedance path to harmonic currents and amplifies them.

Figure 2 shows the harmonic spectrum of current waveform of R-phase of a feeder, located in an industrialised area, with and without 100 KVAr PFC capacitor banks. The industry where the measurements were taken was supplied by a $500 \mathrm{kVA}$ transformer. From Figure 2, it can be seen that $3^{\text {rd }}, 5^{\text {th }}$ and $7^{\text {th }}$ harmonic components have significantly increased in the presence of PFC capacitors.

\section{Analysis on industries as a whole}

Instantaneous harmonic analysis: Table 6 shows the average harmonics $\mathrm{THD}_{\mathrm{V}}$ and $\mathrm{THD}_{\mathrm{I}}$ for each factory.

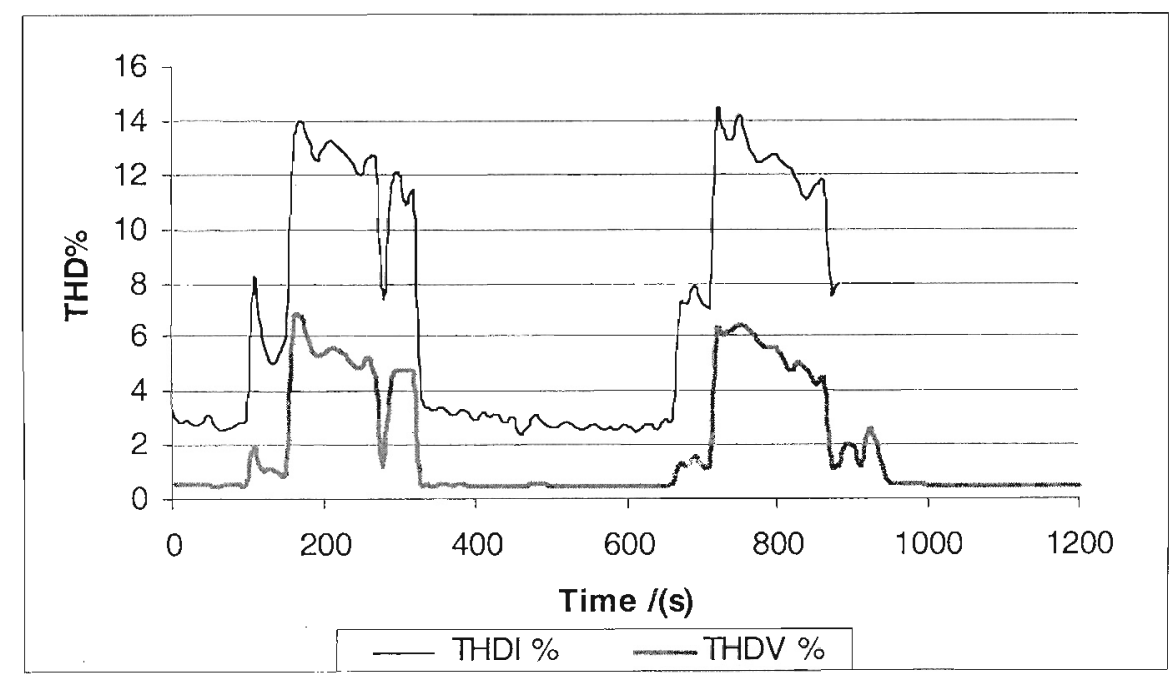

Figure 1: $\mathbf{T H D}_{\mathrm{I}}$ and $\mathrm{THD}_{\mathrm{v}}$ variation with time for dc-motor drive 


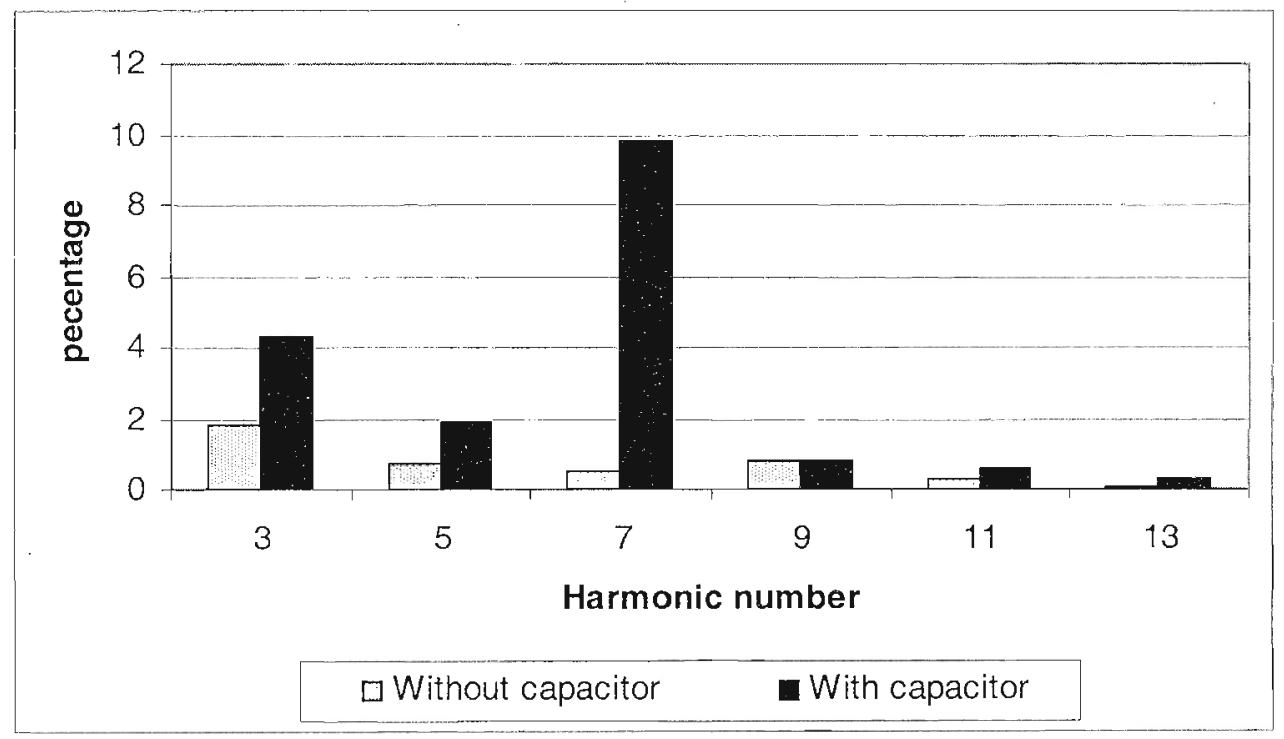

Figure 2: Harmonic spectrum of the Current waveform with and without a PFC capacitor unit

From the spot measurement given in Table 6 and continuous measurements shown in Figure 3, it is clear that almost all the companies are having average $T D D_{I}$ above the lowest possible limit (5\%) as stated in IEEE 519. Further, in most of the companies, $\mathrm{THD}_{\mathrm{I}}<11 \%$, are exceeding the specified margin in IEEE 519.

Figure 4 shows the time variation of $\mathrm{THD}_{\mathrm{V}}$, and it clearly shows that the $\mathrm{THD}_{\mathrm{V}}$ is under the limits specified by IEEE 519. From supplier point of view, the concern on harmonic is not so alarming.

Even though, $\mathrm{THD}_{\mathrm{v}}$ is smaller, $\mathrm{THD}_{\mathrm{I}}$ exceeds the specified limits in IEEE 519. Normally when $\mathrm{THD}_{1}$ is larger; it is expected to have larger $\mathrm{THD}_{\mathrm{V}}$, but it was not observed here. This can be resonated in two ways:

a) The company may be located in a nonindustrialised zone, and therefore most of the

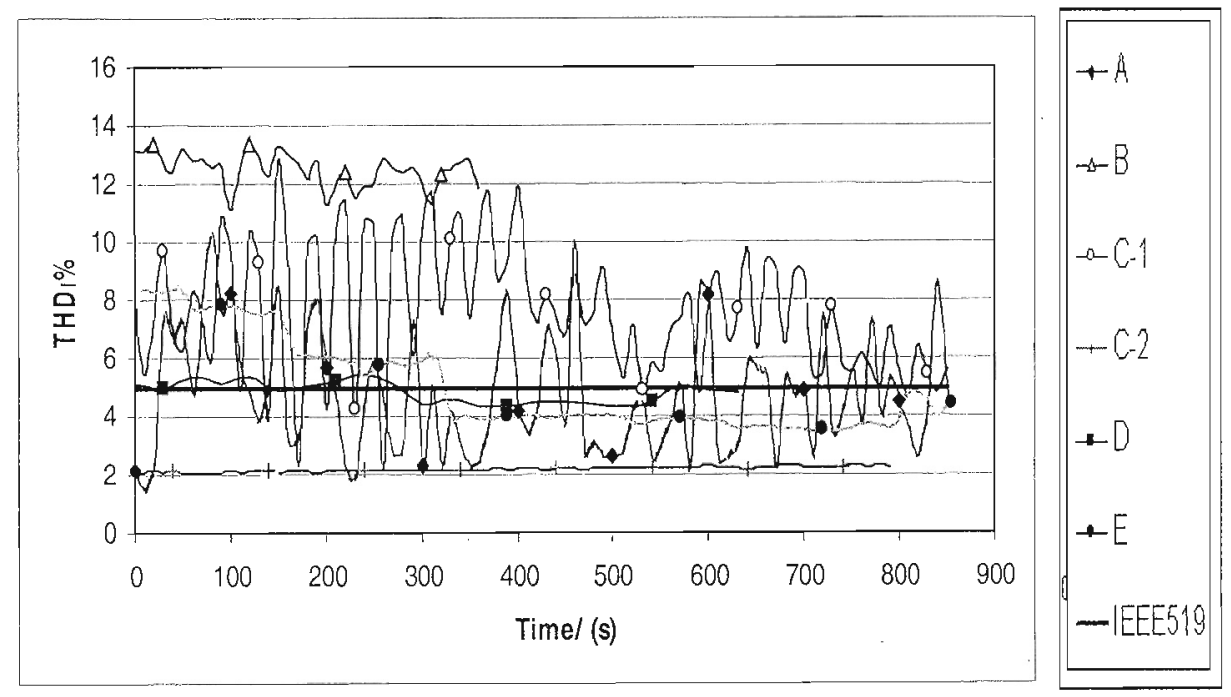

Figure 3: $\mathrm{THD}_{\mathrm{I}} \%$ with time for five different industries 


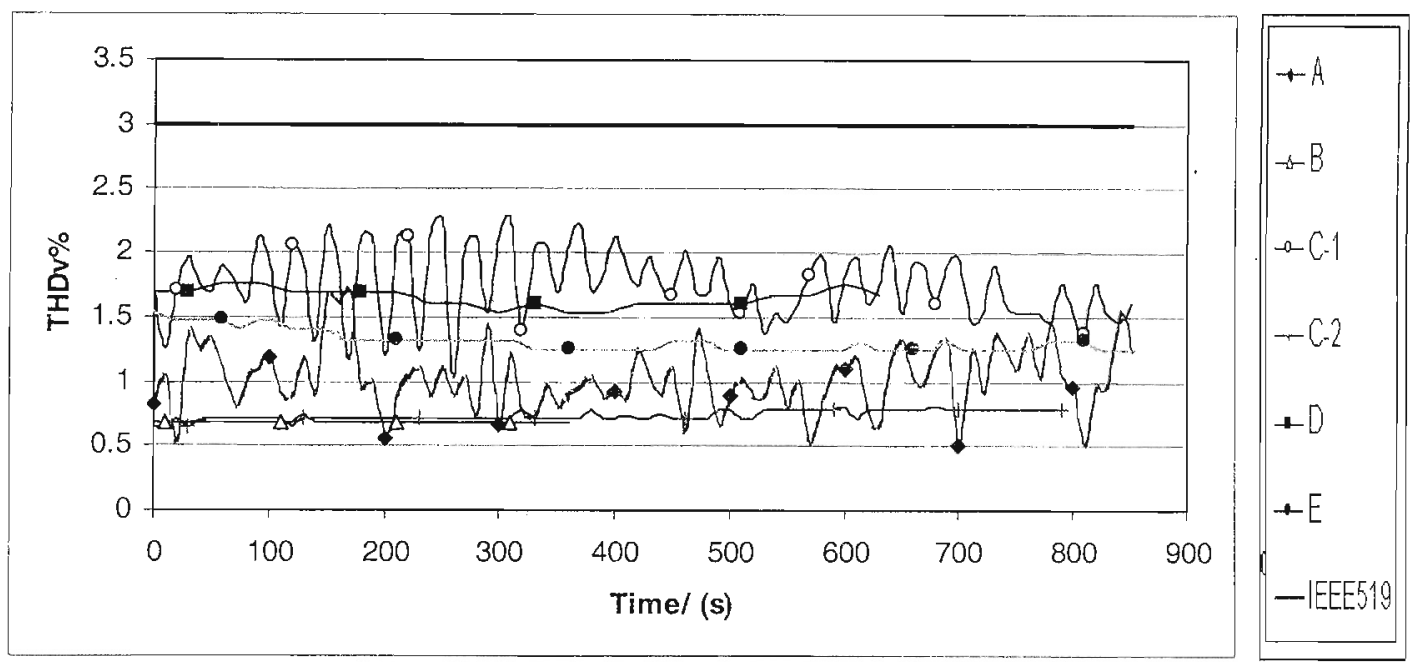

Figure 4: THD $_{\mathrm{v}} \%$ with time for five different industries

surrounding loads are liner and harmonic currents are not comparable with fundamental current drawn from common bus thus reduces $\mathrm{THD}_{\mathrm{v}}$. This can be supported with the observation from the company $\mathrm{B}$, which is a tea factory located in a non-industrialised zone having low $\mathrm{THD}_{\mathrm{v}}$ and high THD $_{1}$. But in some cases this is not hold where system strength is very poor.

b) Other possibility is when the system strength is higher, that is source impedance is low, companies can generate large harmonic levels without effecting to the $\mathrm{THD}_{\mathrm{v}}$. Even though $\mathrm{THD}_{\mathrm{I}}$ limit is specified as $5 \%$ for a weaker system, with a stronger system it can be reached to a higher level as specified in IEEE 519. Therefore, in order to determine the correct limit on $\mathrm{THD}_{\mathrm{I}}$, the knowledge of the short circuit level at the point of connection is necessary.

From the observations on $\mathrm{THD}_{\mathrm{v}}$ and $\mathrm{THD}_{\mathrm{I}}$, harmonic levels are approaching the acceptable limits specified in the standards. Therefore, if expansions are taken place in a factory, then further analysis on individual harmonic levels is necessary to minimise the effect of harmonics both on the consumers themselves and the utility.

In Table 6, almost all the companies' show very low $2^{\text {nd }}$ order harmonics. This is due to the odd symmetry of the current waveform. Triplex harmonics are lower in all the companies except $\mathrm{D}$ and $\mathrm{C}-2$, since both companies use significant amount of single-phase non-linear loads. The lower triplex harmonic is due to the three-phase three wire delta-connected loads such as induction motors connected in most of the factories. The triplex harmonics can, in the long run, reduce the life of induction motors and increase the neural wire overheating.

From Table 6, a higher fifth and seventh order harmonic levels can be observed and this is reconfirmed by Figures 5 and 6 . These two are the most dominant harmonic current components, and both harmonics are approaching G5/3 limits. The VSD and other rectifier loads are the main loads producing fifth and seventh order harmonics. These harmonic currents are amplified by PFC capacitor bank. This is why companies B, $\mathrm{C} 1$ and $\mathrm{D}$ have higher $5^{\text {th }}$ and $7^{\text {th }}$ order harmonics.

With the increasing penetration of VSD and other non-linear loads in the future, the consumers have to pay more attention to minimise the effects of $5^{\text {th }}$ and $7^{\text {th }}$ order harmonics. All the other higher order harmonics are significantly below the G5/3 limits; therefore less attention was paid on those harmonics in this paper.

The harmonics effects on sensitive loads depend on both magnitude and duration of exposure. ${ }^{16}$ Therefore, to investigate the effects 
Table 4: Measured average fundamental, harmonic currents and $\mathrm{THD}_{\mathrm{I}}$

\begin{tabular}{|c|c|c|c|c|c|c|c|c|c|}
\hline \multirow[b]{2}{*}{$\begin{array}{l}\text { Description } \\
\text { of the load }\end{array}$} & \multirow[b]{2}{*}{$\begin{array}{l}\text { Fundamental } \\
\text { current (A) }\end{array}$} & \multicolumn{8}{|c|}{ Percentage harmonic content } \\
\hline & & $2^{\text {nd }}$ & $3^{\mathrm{rd}}$ & $5^{\text {th }}$ & $7^{\mathrm{th}}$ & $9^{\text {th }}$ & $11^{\mathrm{th}}$ & $13^{\text {th }}$ & THD \\
\hline $\begin{array}{l}\text { VSD }(15 \mathrm{~kW}) \\
\text { Three-phase }\end{array}$ & 21.4 & 1 & 2.8 & 55 & 36 & 0.5 & 12 & 7.6 & 72.9 \\
\hline $\begin{array}{l}\text { DC motor drive } \\
(375 \mathrm{~kW}) \text { Three-phase }\end{array}$ & 450.0 & 0.3 & 0.3 & 7.7 & 1.9 & 0.1 & 0.1 & 0.5 & 7.9 \\
\hline $\begin{array}{l}\text { Personal computer } \\
\text { (10 Nos)Single-phase }\end{array}$ & 2.7 & 0.5 & 73.7 & 36.8 & 5.7 & 13.3 & 10.7 & 2.1 & 85.7 \\
\hline $\begin{array}{l}\text { Florescent lamps with } \\
\text { Electronic Ballast } \\
(16 \times 36 \text { W)Single-phase }\end{array}$ & 2.6 & 2 & 14 & 6 & 8 & 0.5 & 3 & - & 19.7 \\
\hline $\begin{array}{l}\text { 5CFL lamps }(5 \times 20 \mathrm{~W}) \\
\text { Single-phase }\end{array}$ & 0.4 & 1 & 64.5 & 46.9 & 42.1 & - & 24.2 & 10.9 & 99.9 \\
\hline
\end{tabular}

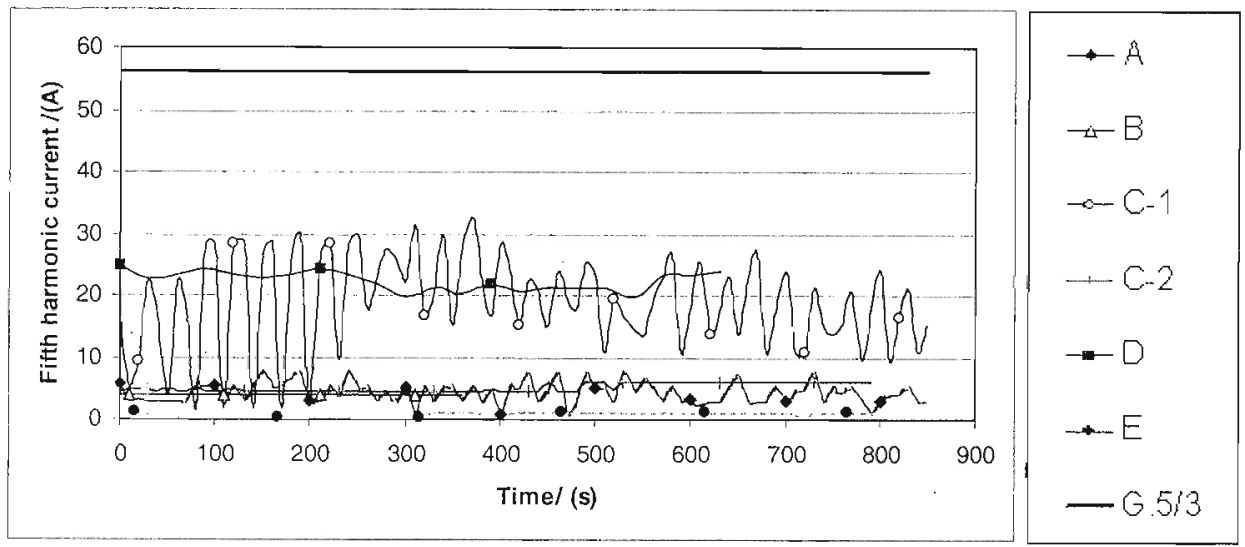

Figure 5: Variation of fifth order harmonic current with time

of harmonics properly, it is necessary to study the probability of occurrence of harmonics.

Probability analysis: The continued harmonic distortion over a long period may cause malfunction to the sensitive equipment. However, a higher THD level that decreases after a relatively short duration of time may not affect the consumer or the utility equipment adversely. In order to assess this, statistical methods are normally used.

Figure 7 shows the histogram of $\mathrm{THD}_{\mathrm{v}}$ and Figure 8 shows the cumulative relative frequency distribution of $\mathrm{THD}_{\mathrm{v}}$ in company $\mathrm{C}$ panel-1, where the cumulative frequency is defined as the percentage of $\mathrm{THD}_{\mathrm{v}}$ observation "less than or equal" to a given value of the variable. The histogram gives percentage of occurrence of a particular value of $\mathrm{THD}_{\mathrm{v}}$ while the cumulative frequency distribution enables us to see how many observations lie below a certain value of ${ }^{r} \mathrm{TD}_{\mathrm{V}}$.

With cumulative probability distribution graph, the time duration of THD exceeding a particular THD level can be determined, provided that duration of "ON time" of machine is known. This can be used to judge the suitability of sensitive equipment for the supply considered. For an example, the company $\mathrm{C}-1$ intends to purchase 


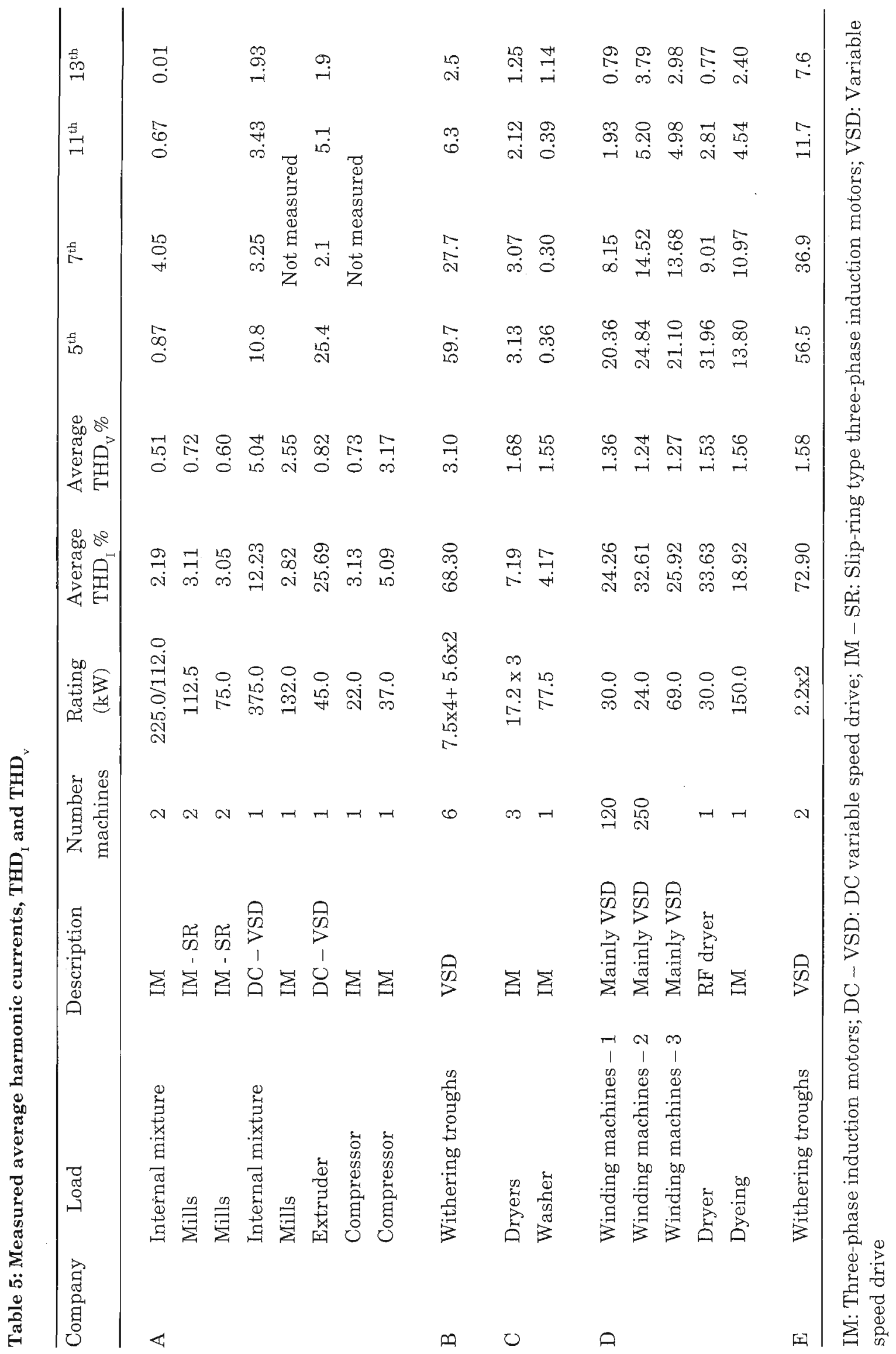




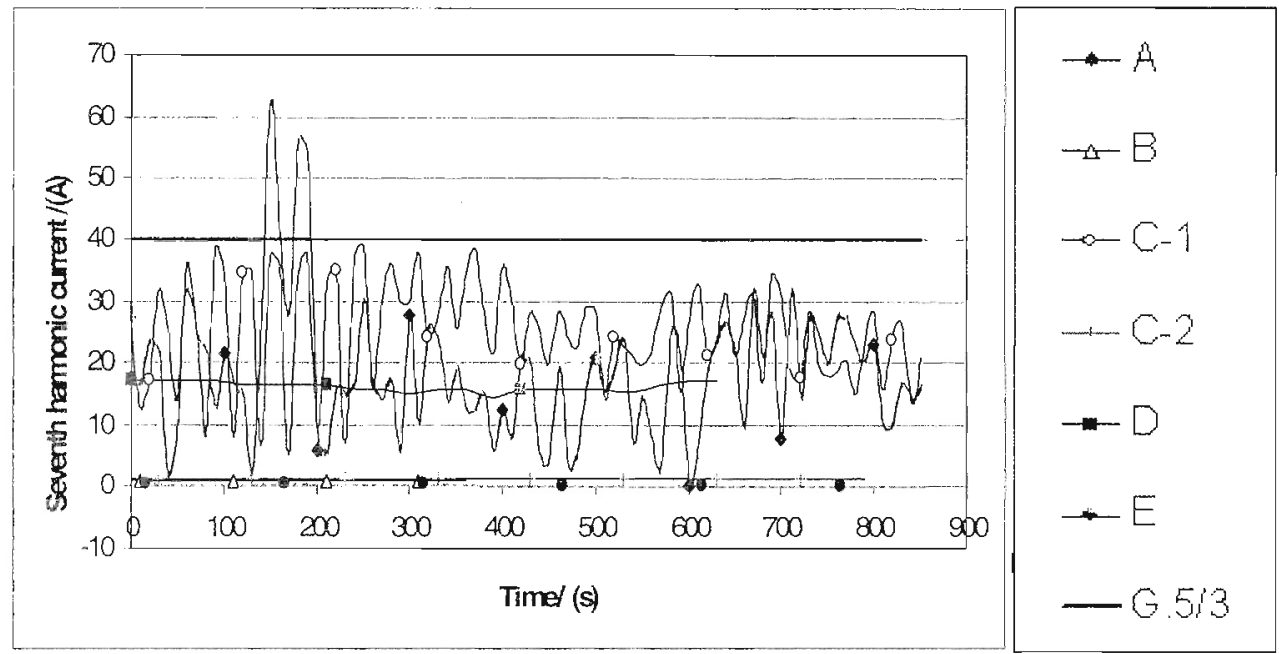

Figure 6: Variation of seventh order harmonic current with time

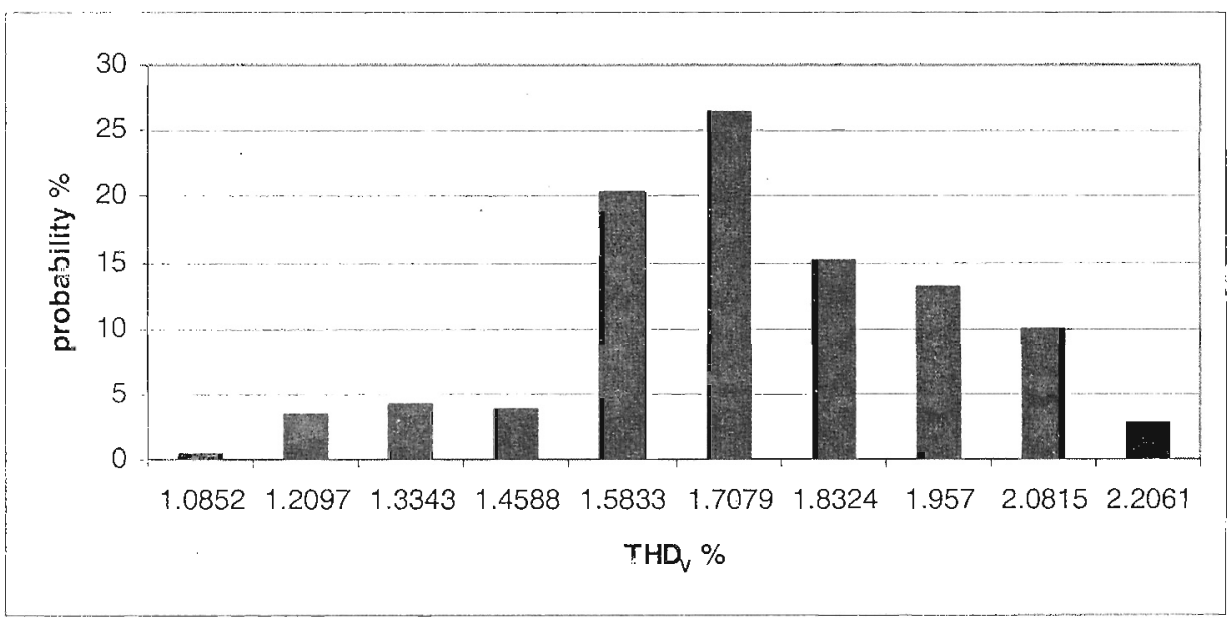

Figure 7: Histogram of $\mathrm{THD}_{\mathrm{v}}$ of Company $\mathrm{C}$-1

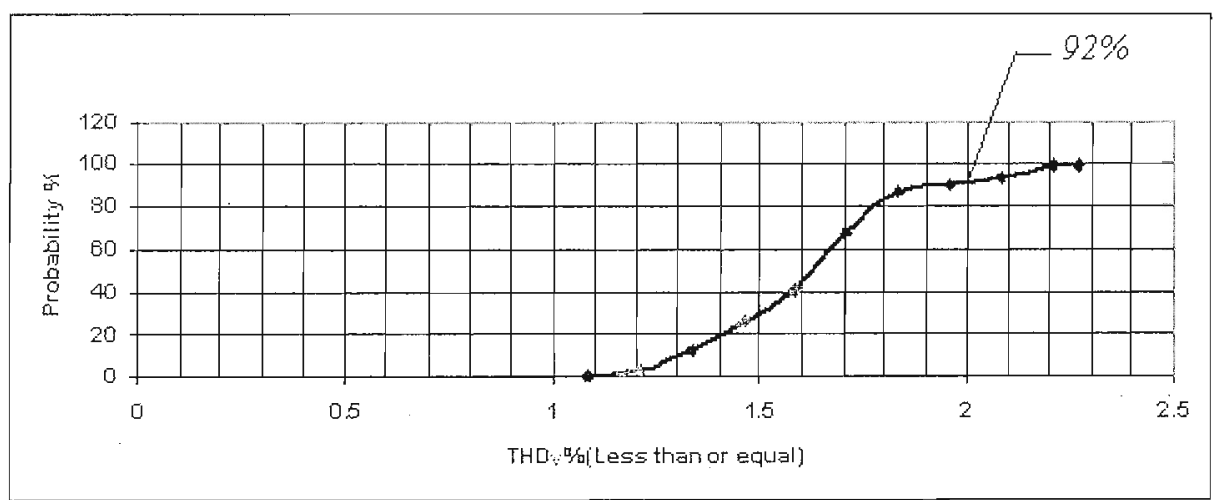

Figure 8: Cumulative relative probability distribution of $\mathrm{THD}_{\mathrm{v}}$ company $\mathrm{C}$-1 
Table 6: Harmonic current magnitudes for five different industries

\begin{tabular}{lcccccc}
\hline Current/(A) & $\mathrm{A}$ & $\mathrm{B}$ & & $\mathrm{C}$ & $\mathrm{D}$ & $\mathrm{E}$ \\
\cline { 4 - 7 } & \multicolumn{7}{c}{ Pannel-1 } & Pannel-2 & & \\
\hline & & & & & & \\
Fundamental & 492 & 34.5 & 497 & 0.16 & - & 0.35 \\
$2^{\text {nd }}$ Order & 1.19 & 0.193 & 0.582 & 7.83 & 7.83 & 0.36 \\
$3^{\text {rd }}$ Order & 0.31 & 0.12 & 2.10 & 5.18 & 22.3 & 1.10 \\
$5^{\text {th }}$ Order & 4.26 & 4.00 & 18.8 & 1.20 & 16.1 & 3.20 \\
$7^{\text {th }}$ Order & 18.3 & 0.81 & 24.9 & 2.3 & 0.14 & 0.05 \\
$9^{\text {th }}$ Order & 0.36 & 0.13 & 1.7 & 0.13 & 6.37 & 0.69 \\
$11^{\text {th }}$ Order & 3.07 & 0.13 & 12.3 & 0.18 & 0.17 & 0.36 \\
$13^{\text {th }}$ Order & 0.02 & 0 & 1.85 & 0.74 & 1.65 & 1.39 \\
V THD \% & 1.01 & 0.67 & 1.74 & 2.21 & 4.82 & 5.2 \\
I THD \% & 4.71 & 12.5 & 7.58 & 1.38 & 4.21 & 4.92 \\
I THD <11 & 3.43 & 11.9 & 5.65 & & & \\
\hline
\end{tabular}

a new DSP controlled machinery, then the company can inform the supplier about their $\mathrm{THD}_{\mathrm{v}}$ distribution using the above figures. If a particular machinery, which requires a supply where the $\mathrm{THD}_{\mathrm{v}}$ level should not exceed $2 \%$ for more than $5 \%$ of its operating time, then that equipment cannot be installed in this factory. It is because, as indicated in Figure 8, $8 \%$ of time the supply is exceeding the $\mathrm{THD}_{\mathrm{v}}$ by $2 \%$.

\section{DISCUSSION}

In the harmonic study, it was found that the current harmonics level of individual industries is significantly high. Further, the voltage harmonic level is approaching the limits specified in IEEE 519 standard. Therefore, in order to reduce the threat to the quality of the supply voltage, the future expansion will require further analysis of harmonic current penetration.

Individual consumers are responsible for keeping the current harmonics produced by their own equipment within the specified limits. The harmonics produced by each industry can be reduced by employing compensation devices at the point of connection. Active power filters are becoming popular as harmonic elimination equipment. ${ }^{17}$
Utility has a responsibility to damp harmonics propagated in the power distribution system. Otherwise harmonic penetrated into the system may have adverse effect on the neighbouring loads as described in section 2 . Therefore, most of the utilities have imposed limits for harmonic penetration levels by introducing different standards. ${ }^{5,6}$ These limits forces the consumers to implement measures to reduce harmonic penetrated into the power system. The simplest approach of reducing the harmonic is to use tuned passive filters. However, this method can be used only to reduce specific frequency components, whereas installing an active power filter in substations and/or on distribution feeders eliminate all frequency harmonics at the point of connection. These types of systems are being used in Japan, ${ }^{18,19}$

\section{CONCLUSION}

Harmonic measurements were taken in individual loads and in a number of industries in Sri Lanka, which covers major industrial sectors. These measurements can on the one hand be used by the consumers to minimize the effect of harmonics on the equipment connected to their premises or to decide the actions required when connecting new equipment. On the other hand, utilities can 
clearly see the trends in harmonic pollution level in various industries and can take necessary actions to minimize or mitigate the effects caused by harmonics to the power distribution network.

Careful consideration must be given to connect new loads to the existing installations. Harmonic profiles of various loads given in this paper may be useful to estimate the harmonic contribution from various industries with addition of new loads. However, it is recommended to make in- house measurement as harmonic contribution from a particular equipment may vary with the configuration, brand, electronic circuits involved and so on. If estimates show that harmonic levels are increasing adversely, alternatives or harmonic elimination techniques need to be considered.

Measurement on industries as a whole indicates that the harmonic level in most of them is reaching the limits specified in international standards such as IEEE 519 and G.5/3. Therefore, in order to minimize the adverse consequence of harmonic pollution, utilities must act now itself. Utilities must impose limits specified by the most appropriate standard for Sri Lanka among the existing international standards. If it is difficult to make an international standard statutory, then a suitable Sri Lankan standard must be drawn. Afterwards, all the new installations must be checked against the harmonic standard before giving electricity connections. Further, harmonic analysing equipment should be connected to the existing installations for continuous monitoring, mainly in installations such as industrial parks. These measurements can be used to introduce mitigation action if necessary. If utilities do not act quickly, these harmonics will not only become a nuisance to the power network but also the harmonic losses will demand more power generation.

Further, power factor correction capacitors are commonly connected to reduce the electricity bills. A case study was introduced to illustrate the adverse effects that can cause due to resonance of these capacitors with the inductors in the circuit. Resonances will amplify the certain harmonics components, which has many negative effects on the power distribution system.

\section{References}

1. Carroll E. I. (1999). Power electronics for very high power applications. Power Engineering Journal 13(2): $81-87$.

2. Shakweh Y. (1999). Power devices for medium voltage PWM converters. Power Engineering Journal 13(6): 297 - 307.

3. Bose B. K. (1992). Power Semiconductor Devices and Power Integrated Circuits. In: Modern Power Electronics, Evolution, Technology, and Applications, A Selected Reprint Volume, IEEE Industrial Electronics Society, (Book), ISBN 087942-282-3, IEEE: 125 - 214.

4. Smith K. S. \& Ran L. (1998). PWM drives: Voltage type harmonic sources in power systems, IEE Proceedings on Generation Transmission and Distribution, 145(3): 293 - 299.

5. IEEE (1992). Recommended Practices and Requirements for Harmonic Control in Electrical Power Systems, IEEE STD 519: 75 - 100.

6. "Limits for harmonics in the UK electricity supply system", Engineering recommendation G $5 / 3,1979$.

7. Maule D. (2001). Regulating mains pollution, IEE review, March 35 - 38 .

8. Detjen D., Joep J. \& Rik W. De Doncker (2001). A new hybrid filter to dampen resonances and compensate harmonic currents in industrial power systems with power factor correction equipment, IEEE sixteenth annual Applied Power Electronics Conference and Exposition (APEC), 2001, 2: 563 - 569.

9. Czarnecki L. S. (1997). Effect of minor harmonics on the performance of resonant harmonic filters in distribution systems, IEE Proceeding on Electric Power Applications 144(5): 349 - 356.

10. Mohan N., Undeland T.M. \& Robbins W.P. (2001). Power Electronics Converters, Applications and Design second edition, John Wiley \& Sons: $416-417$.

11. Lucas J.R. \& Wijekoon V.B. (1995). Power factor and harmonic distortion of compact fluorescent lamps, Trans IESL, Vol. 1, Part B, p 29-37. 
12. Girgis A.A., Clapp M.C., Makram E.B., Qiu J., Dalton J.G. \& Catoe R. C. (1990). Measurement and characterization of harmonic and high frequency distortion for a large industrial load, IEEE Transactions on Power Delivery, 5(1): 427 -434 .

13. Trzynadlowski A.M. (2001). Preface, Control of Induction Motors, Academic Press series in Engineering.

14. McNerney G. \& Richardson R. (1992). The statistical smoothing of power delivered to utilities by multiple wind turbines, IEEE Transactions on Energy Conversion, 7(4): 644 647.

15. Inaba H., Shima S., Ueda A., Ando T., Kirosawa T. \& Sakai Y. (1985). A new Speed Control System for DC Motors Using GTO Converter and its Application to Elevators, IEEE Transactions on Industry Applications, IA-21(2): 391 - 397.
16. Sabin D.D., Brooks D.L. \& Ashok Sundram(1999). Indices for Assessing Harmonic Distortion from Power Quality Measurements: Definitions and Benchmark Data IEEE Transaction on Power Delivery, 14(2): 489-496.

17. Prasad A R, Ziogas P. D. \& Manlas S. (1989). An Active Power Factor Correction Techniques for Three-Phase Diode Rectifiers IEEE Power Electronics Specialised Conference (PESC) 58-66.

18. Akagi H. (1996). New Trends in Active Filters for Power Conditioning", IEEE Transactions on Industrial Applications, 32(6): 1312.

19. Bhattacharya S., Frank T. M., Divan D. M., Banerjee B. (1998). Active Filter System Implementation, IEEE Industrial Application Magazine, p 47. 